\title{
Capacidade extratora de plantas em sistemas alagados utilizados no tratamento de águas residuárias de laticínios
}

\author{
Antonio T. de Matos ${ }^{1}$, Sérgio S. Abrahão ${ }^{2}$, Paola A. V. Lo Monaco ${ }^{3}$, \\ Antover P. Sarmento ${ }^{4} \&$ Mateus P. de Matos ${ }^{5}$
}

\begin{abstract}
RESUMO
O bjetivou-se, neste trabalho, avaliar a capacidade extratora de duas espécies vegetais quando cultivadas em sistemas alagados construídos $(\mathrm{SAC})$ utilizados no tratamento de águas residuárias de laticínios (ARL). As unidades experimentais foram constituídas por cinco SAC cultivados com capim el efante (Pennisetum purpureum schum) e cinco SAC cultivados com capim tifton 85 (Cynodon spp.), com escoamento subsuperficial horizontal. A ARL foi aplicada numa vazão média de $60 \mathrm{~L} \mathrm{~d}^{-1} \mathrm{e}$ tempo de residência hidráulica de 4,8 dias, sendo os SAC submetidos a Taxas de Carregamento Orgânico (TCO) de $66,130,190,320$ e $570 \mathrm{~kg} \mathrm{ha}^{-1} \mathrm{~d}^{-1}$ de DBO. 0 capim tifton 85 extraiu mais nitrogênio e sódio enquanto o capim el efante extraiu maior quantidade de potássio da ARL, quando cultivado sob as taxas de carregamento orgânico (TCO) avaliadas. A concentração de fósforo na parte aérea e a capacidade extratora foram semelhantes nos dois capins; entretanto, existem evidências de aumento na capacidade de extração desse nutriente pelo capim tifton 85, com o aumento da TCO aplicada nos SAC.
\end{abstract}

Palavras-chave: tratamento de resíduos, sistemas wetlands, processamento do leite

\section{Extraction capacity of plants grown in constructed wetland systems used for treatment of dairy wastewater}

\begin{abstract}
The objective of this research was to evaluate the extraction capacity of two plant species when grown in constructed wetland systems (CWS) used for dairy wastewater (DW) treatment. The experimental units were formed by five CW S grown with Pennisetum purpureum schum grass and five CW S cultivated with grass tifton 85 (Cynodon spp.), with horizontal subsurface flow. The DW was applied at an average flow of $60 \mathrm{~L} \mathrm{~d}^{-1}$ and hydraulic residence time of 4.8 days, and subjected to organic loading rates $(O R L)$ of 66 , $130,190,320$ and $570 \mathrm{~kg} \mathrm{ha}^{-1} \mathrm{~d}^{-1}$ of BOD. The grass tifton 85 extracted more nitrogen and sodium, while the elephant grass extracted a larger amount of potassium from the DW, when grown under the evaluated organic loading rates $(\mathrm{ORL})$. The concentration of phosphorus in aerial parts of plants and extraction capacity were similar in the two grasses, however, there is evidence of an increase in the extraction this nutrient, by the grass tifton 85 , with the increase of the O RL applied in the CW S.
\end{abstract}

Key words: waste treatment, wetland systems, milk processing

\footnotetext{
DEA/UFV. Av. PH Rolfs, s/n, Fone: (31) 3899-1886. E-mail: atmatos@ufv.br

Mestre em Engenharia Agrícola/U FV. Fone: (31) 3891-2000. E-mail: sergio@ctazm.com.br

${ }^{3}$ Instituto Federal de Educação/Ciência e Tecnologia do Espírito Santo. Fone: (31) 3899-1871. E-mail: paolalomonaco2004@yahoo.com.br

${ }^{4}$ D outorando em Engenharia Agrícola/U FV. Fone: (31) 3899-1871. E-mail: antoverps@hotmail.com

${ }^{5}$ Graduando em Engenharia Agrícola e Ambiental/U FV. Fone: (31) 3899-1886. E-mail: mateus.matos@ufv.br
} 


\section{INTRODUÇÃO}

O uso da água no processamento de alimentos gera grandes quantidades de efluentes líquidos, que necessitam ser tratados antes do seu lançamento em corpos hídricos receptores. Dentre as indústrias alimentícias, a contribuição dos laticínios na poluição dos corpos hídricos é muito expressiva, visto que o beneficiamento do leite gera considerável carga poluidora, decorrente da presença de grande quantidade de compostos orgânicos em suspensão nas águas residuárias.

O volume de água residuária gerado na atividade pode variar de 1 a 5 vezes o volume de leite processado, dependendo do produto final e do nível tecnológico da indústria de laticínios e, com base na carga poluente que essas águas possuem, pode-se inferir que grandes impactos ambientais podem ser gerados se elas não forem adequadamente tratadas e dispostas no ambiente. No que se refere ao aspecto qualitativo, as opções para tratamento ou recuperação de águas servidas envolvem inúmeras e diferentes alternativas, muitas delas onerosas e complexas e outras de baixo custo e simples. Deve-se destacar, dentre essas alternativas, o uso de Sistemas Alagados Construídos (SAC) ou sistemas Wetland (Matos et al., 2008).

Os SAC têm sido propostos e utilizados no tratamento de várias águas residuárias, tais como as domésticas (Brasil et al., 2005; 2007; Brasil \& Matos, 2008; Konnerup et al., 2009), de laticínios (Matos et al., 2008), da lavagem/despolpa de frutos do cafeeiro (Fia et al., 2008; 2010), suinocultura (Matos et al., 2009; 2010a; 2010b) e outras. Dentre os componentes fundamentais desses sistemas estão as macrófitas aquáticas neles cultivadas, o substrato e o biofilme de bactérias formado no meio responsáveis, direta ou indiretamente, pela ocorrência dos mecanismos de remoção de poluentes associados a esses sistemas. A escolha da espécie vegetal é, juntamente com outras variáveis de dimensionamento, de fundamental importância para o sucesso do tratamento de águas residuárias em SAC. Dentre as funções das macrófitas aquáticas, estão incluídas a extração de nutrientes contidos na água residuária; a transferência de oxigênio para o substrato; servir de suporte (rizomas e raízes) para o crescimento de biofilme de bactérias, além de melhoria na permeabilidade do substrato e na estética do ambiente (Matos et al., 2009).

As plantas utilizam nutrientes das águas residuárias para o seu crescimento, atuando, deste modo, como extratoras de grande parte dos macro e micronutrientes da água residuária em tratamento. Segundo Lautenschlager (2001), a extração de nutrientes pelas plantas é um dos principais fatores responsáveis pela reciclagem de sais minerais. Essas plantas podem, ainda, extrair ou possibilitar a transformação de substâncias contendo metais pesados e compostos orgânicos tóxicos. No período de crescimento, as plantas podem absorver macronutrientes ( $\mathrm{Ne} \mathrm{P}$ ) e micronutrientes (incluindo metais) sendo que, no início da senescência, a maior parte dos nutrientes é translocada para as raízes e rizomas.

Em alguns trabalhos envolvendo o tratamento de águas residuárias por disposição no solo, espécies vegetais como o capim tifton 85, Cynodon spp. (Drumond et al., 2006; Matos et al., 2004; 2008; 2010b; Queiroz et al., 2004) e o capim elefante,
Pennisetum purpureum (Brasil et al., 2007; Matos et al., 2008) têm demonstrado elevada eficiência na extração de nutrientes e poluentes de águas residuárias de diversas origens.

Por haver pouca informação sobre a produtividade e a capacidade de plantas cultivadas em sistemas alagados construídos na remoção de poluentes de águas residuárias objetivou-se, neste trabalho, avaliar a capacidade extratora de poluentes do capim tifton 85 (Cynodon spp) e do capim elefante cv. Napier (Pennisetum purpureum schum) quando submetidos a diferentes aplicações de carga orgânica no tratamento de águas residuárias de laticínios em sistemas alagados construídos.

\section{Material e MÉTOdos}

O experimento foi conduzido na Área Experimental de Hidráulica, Irrigação e Drenagem do Departamento de Engenharia Agrícola da Universidade Federal de Viçosa, em Viçosa, Minas Gerais.

Para a realização dos estudos, utilizaram-se águas residuárias brutas provenientes da Usina de Beneficiamento de Leite da Fundação Arthur Bernardes (Laticínios da FUNARBE), localizada no Campus da UFV, coletadas numa caixa de passagem na qual se acumula todo o efluente originado dos diversos setores de produção do laticínio.

$\mathrm{O}$ experimento foi conduzido em dez leitos de sistemas alagados construídos (SAC) com escoamento subsuperficial horizontal para tratamento secundário/terciário de água residuária de laticínios (ARL). Cada SAC foi constituído por um tanque de 0,40 $\mathrm{m}$ de altura, por $0,75 \mathrm{~m}$ de largura e 3,00 $\mathrm{m}$ de comprimento, impermeabilizado, preenchido com substrato de brita zero (diâmetro $-\mathrm{D}_{60}=7,0 \mathrm{~mm}, \mathrm{CU} \mathrm{D}_{60} / \mathrm{D}_{10}=1,6$ e volume de vazios de $48,4 \%$ ), declividade de base de $0,5 \%$ no sentido longitudinal do tanque e profundidade do leito filtrante de 0,33 m. As unidades experimentais se compunham de cinco SAC cultivados com capim elefante (Pennisetum purpureum schum) (CEF) e cinco SAC cultivados com capim tifton 85 (Cynodon spp.) (CTF).

A água residuária afluente aos $\mathrm{SAC}$ foi aplicada nos tanques na vazão média de $60 \mathrm{~L} \mathrm{~d}^{-1}$ e tempo de residência hidráulica igual a 4,8 dias. As taxas de carregamento orgânico aplicadas (TCO) nos SAC foram de 66, 130, 190, 320 e $570 \mathrm{~kg} \mathrm{ha}^{-1} \mathrm{~d}^{-1} \mathrm{de}$ DBO. Obtiveram-se as cargas orgânicas dos afluentes por meio de misturas da água residuária do laticínios bruta (ARL), que tinha DBO de aproximadamente $2.500 \mathrm{mg} \mathrm{L}^{-1}$, com água "limpa" captada em manancial de água superficial (AM), conforme apresentado na Tabela 1.

Nas coletas em que a água residuária bruta do laticínio apresentou valor de $\mathrm{DBO}_{5}$ inferior a $2.500 \mathrm{mg} \mathrm{L}^{-1}$ foi necessária a adição de soro de leite para a equalização da ARL a ser aplicada nos SAC. Do tanque de equalização a ARL foi conduzida diariamente até o reservatório de dosagem de cada SAC. Cada reservatório recebia o volume de $\mathrm{ARL}$ correspondente à TCO a ser aplicada e o complemento de água do manancial (AM) até ser atingido o volume de $60 \mathrm{~L}$ (Tabela 1). Com base nesse volume, o tempo de residência hidráulica foi estimado como de 4,8 dias, calculado considerando-se apenas a porosidade do 
Tabela 1. Taxas de carregamento orgânico médio superficial (TCO) e médio volumétrico (TCO v), expressas em termos de $\mathrm{DBO}_{5}$ e DQO (entre parênteses) e volumes aplicados diariamente de água residuária do laticínios (ARL) e água do manancial (AM)

\begin{tabular}{|c|c|c|c|c|}
\hline \multirow{3}{*}{$\mathrm{SAC}^{*}$} & \multirow{3}{*}{$\begin{array}{c}\text { TCO } \\
\text { média e desvio } \\
\text { padrão } \\
\left(\mathrm{kg} \mathrm{ha}^{-1} \mathrm{~d}^{-1}\right)\end{array}$} & \multirow{3}{*}{$\begin{array}{c}\text { TCOv } \\
\text { média e desvio } \\
\text { padrão } \\
\left(\mathrm{g} \mathrm{m}^{-3} \mathrm{~d}^{-1}\right)\end{array}$} & \multicolumn{2}{|c|}{$\begin{array}{c}\text { Vazão } \\
\text { aplicada }\end{array}$} \\
\hline & & & ARL & AM \\
\hline & & & \multicolumn{2}{|c|}{$\left(L^{-1}\right)$} \\
\hline CTF-570 & $\begin{array}{c}571 \pm 129 \\
(1.053 \pm 67)\end{array}$ & $\begin{array}{c}433 \pm 98 \\
(798 \pm 51)\end{array}$ & 45 & 15 \\
\hline CEF-570 & $\begin{array}{c}571 \pm 129 \\
(1.053 \pm 67)\end{array}$ & $\begin{array}{c}433 \pm 98 \\
(798 \pm 51)\end{array}$ & 45 & 15 \\
\hline CTF-320 & $\begin{array}{c}319 \pm 72 \\
(588 \pm 38)\end{array}$ & $\begin{array}{c}242 \pm 54 \\
(445 \pm 29)\end{array}$ & 25 & 35 \\
\hline CEF-320 & $\begin{array}{c}319 \pm 72 \\
(588 \pm 38)\end{array}$ & $\begin{array}{c}242 \pm 54 \\
(445 \pm 29)\end{array}$ & 25 & 35 \\
\hline CTF-190 & $\begin{array}{c}193 \pm 43 \\
(355 \pm 23)\end{array}$ & $\begin{array}{c}146 \pm 32 \\
(269 \pm 18)\end{array}$ & 15 & 45 \\
\hline CEF-190 & $\begin{array}{c}193 \pm 43 \\
(355 \pm 23)\end{array}$ & $\begin{array}{c}146 \pm 32 \\
(269 \pm 18)\end{array}$ & 15 & 45 \\
\hline CTF-130 & $\begin{array}{c}130 \pm 28 \\
(236 \pm 16)\end{array}$ & $\begin{array}{c}98 \pm 21 \\
(179 \pm 12)\end{array}$ & 10 & 50 \\
\hline CEF-130 & $\begin{array}{c}130 \pm 28 \\
(236 \pm 16)\end{array}$ & $\begin{array}{c}98 \pm 21 \\
(179 \pm 12)\end{array}$ & 10 & 50 \\
\hline CEF- 66 & $\begin{array}{c}66 \pm 14 \\
(122 \pm 9)\end{array}$ & $\begin{array}{l}50 \pm 10 \\
(99 \pm 6)\end{array}$ & 5 & 55 \\
\hline CTF- 66 & $\begin{array}{c}66 \pm 14 \\
(122 \pm 9)\end{array}$ & $\begin{array}{l}50 \pm 10 \\
(99 \pm 6)\end{array}$ & 5 & 55 \\
\hline
\end{tabular}

* Sistema alagado construído; CTF - leito cultivado com capim tifton 85 e CEF - leito cultivado com capim elefante. Os números complementares às siglas representam a taxa de carga orgânica estabelecida para aplicação nos SAC

material suporte como volume útil, o que foi mantido constante em todos os SAC.

As variáveis demanda bioquímica de oxigênio $\left(\mathrm{DBO}_{5}\right)$, demanda química de oxigênio (DQO), sólidos totais (ST), sólidos suspensos totais (SST), sólidos dissolvidos totais (SDT) nitrogênio total Kjeldahl (NTK), fósforo total (P-total), potássio $(\mathrm{K})$ e sódio $(\mathrm{Na})$, foram analisadas em amostras da ARL contida no tanque de equalização, da AM e do afluente, coletadas a cada 14 dias, no período de 84 dias (período que compreendeu o final do inverno e a maior parte da primavera de 2005). As análises laboratoriais foram realizadas no Laboratório de Qualidade da Água do Departamento de Engenharia Agrícola da UFV, em conformidade com as recomendações do Standard Methods (APHA, 2005) para as análises da água de manancial, água residuária bruta e afluente dos SAC. As variáveis avaliadas e os respectivos métodos estão descritos a seguir: DBO - quantificação do oxigênio dissolvido pelo método iodométrico (Processo Winkler); DQO - método de oxidação química em refluxo aberto; ST e SST método gravimétrico; SDT - diferença entre os ST e os SST e NTK - processo semimicro Kjeldahl. Após digestão nítricoperclórico da amostra, foram quantificadas as concentrações de $\mathrm{P}_{\text {Total }}$ - espectrofotometria e $\mathrm{Na}$ e $\mathrm{K}$ - fotometria de chama.

As principais características físicas, químicas e bioquímicas da água residuária do laticínios (ARL) e da água de manancial (AM), utilizadas para a dosagem das TCO, estão apresentadas na Tabela 2.
Tabela 2. Características físicas, químicas e bioquímicas da água residuária do laticínio ( $A R L$ ) e da água de manancial (AM) utilizadasno preparo das águas residuárias aplicadas nos SAC

\begin{tabular}{cccc}
\hline \multirow{2}{*}{ Variáveis } & \multirow{2}{*}{ Unidade } & \multicolumn{2}{c}{ Média e desvio padrão } \\
\cline { 3 - 4 } & & ARL & AM \\
pH & --- & $3,78 \pm 0,47$ & $6,94 \pm 0,17$ \\
CE & $\mu \mathrm{S} \mathrm{cm}^{-1}$ & $994 \pm 110$ & $89 \pm 14$ \\
DBO & $\mathrm{mg} \mathrm{L}^{-1}$ & $2.790 \pm 633$ & $12 \pm 4$ \\
DQO & $\mathrm{mg} \mathrm{L}^{-1}$ & $5.143 \pm 328$ & $20 \pm 6$ \\
SS & $\mathrm{mg} \mathrm{L}^{-1}$ & $702 \pm 100$ & $3 \pm 3$ \\
ST & $\mathrm{mg} \mathrm{L}^{-1}$ & $2.407 \pm 442$ & $104 \pm 41$ \\
SD & $\mathrm{mg} \mathrm{L}^{-1}$ & $1.705 \pm 479$ & $101 \pm 43$ \\
NTK & $\mathrm{m} \mathrm{L}^{-1} \mathrm{de} \mathrm{N}^{-1}$ & $89,54 \pm 17,3$ & $3,33 \pm 5,7$ \\
P-total & $\mathrm{mg} \mathrm{L}^{-1} \mathrm{de} \mathrm{P}$ & $22,51 \pm 5,1$ & $0,12 \pm 0,17$ \\
Potássio & $\mathrm{mg} \mathrm{L}^{-1}$ & $66,36 \pm 23,9$ & $3,77 \pm 1,5$ \\
Sódio & $\mathrm{mg} \mathrm{L}^{-1}$ & $107,72 \pm 98,4$ & $8,43 \pm 4,2$ \\
\hline
\end{tabular}

O corte e a amostragem da biomassa produzida pelas espécies vegetais foram realizados separadamente, por espécie vegetal e em datas diferentes, estabelecidas com base no crescimento da parte aérea e início do tombamento natural das plantas. As amostras coletadas do capim elefante foram relativas ao primeiro corte (61 dias após o corte de uniformização da vegetação nos SAC) e, no caso do capim tifton, foram relativas ao segundo corte, efetuado 45 dias após o primeiro corte (cerca de 90 dias após efetuada a uniformização nos SAC cultivados com este capim).

O material vegetal colhido foi constituído pela parte aérea das plantas de toda a área de cultivo $(0,73 \mathrm{~m}$ de largura x $3,00 \mathrm{~m}$ de comprimento) em cada SAC, coletada em uma altura entre 5 e $10 \mathrm{~cm}$ acima do meio suporte. A massa verde de cada SAC foi imediatamente picada, sendo retirada uma amostra de cada subárea para quantificação do conteúdo de água, possibilitando cálculo do conteúdo de matéria seca e, posteriormente, análise da concentração de nutrientes e sódio no tecido vegetal. As amostras foram acondicionadas em sacos de papel identificados e levadas à estufa, sob temperatura de $60{ }^{\circ} \mathrm{C}$, com circulação de ar, até atingir massa constante (présecagem); em seguida, as amostras foram trituradas em moinho tipo "Willey", com peneira de 30 "mesh" e armazenadas em sacos de papel, para posterior quantificação do conteúdo de matéria seca e realização da análise nutricional. Parte da amostra foi retirada e colocada em estufa, sob temperatura de $105^{\circ} \mathrm{C}$, até ser atingida constância na massa, retirando-se, assim, o conteúdo de água residual e se obtendo, com isto, a matéria seca total, em cada tratamento. A capacidade das plantas em extrair nutrientes foi obtida pelo produto da concentração do nutriente na planta e a produtividade da matéria seca.

Na Tabela 3 estão apresentados os valores de produtividade acumulada do capim tifton 85 e de matéria seca dos capins tifton 85 (soma do que foi obtido nos primeiro e segundo cortes) e elefante (valor obtido em corte único), em função dos valores das TOC aplicadas nos SAC.

As análises do tecido vegetal foram realizadas no Laboratório de Solo e Resíduos Sólidos do Departamento de Engenharia Agrícola da UFV, em conformidade com as recomendações de Kiehl (1985), quantificando-se o nitrogênio total pelo processo semimicro Kjeldahl. As concentrações de 
Tabela 3. Produtividade acumulada de matéria seca dos capins tifton 85 ( 2 cortes) e el efante (1 corte), em função das taxas de carga orgânica superficial (TCO) aplicadas

\begin{tabular}{ccc}
\hline TCO & \multicolumn{2}{c}{ Produtividade $\left(\right.$ Mg ha $\left.^{-1}\right)$} \\
\cline { 2 - 3 } (kg ha $^{-1} \mathbf{d ~}^{-1}$ de DBO) & Capim Tifton 85 & Capim Elefante \\
66 & 7,5 & 8,1 \\
130 & 11,0 & 9,4 \\
190 & 10,5 & 4,9 \\
320 & 14,8 & 7,5 \\
570 & 14,9 & 8,6 \\
\hline
\end{tabular}

fósforo, potássio e sódio, foram quantificadas após digestão nítrico-perclórico da amostra e medição, respectivamente, em espectrofotômetro e em fotômetro de chama.

Por meio de regressão linear e não linear, fez-se o ajuste de equações matemáticas relacionando-se concentração na parte aérea e de extração de nutrientes e sódio pelos vegetais, em função da TCO aplicada, tendo-se considerado satisfatório o ajuste que proporcionasse comportamento biológico explicável, apresentasse um coeficiente de determinação maior que $70 \%$ e apresentasse significância mínima de 10\% de probabilidade nos coeficientes; enfim, para se realizar a análise de regressão utilizou-se o programa SigmaPlot 9.0.

\section{RESULTADOS E DISCUSSÃO}

Tem-se, na Figura 1A, os valores de concentração média e, na Figura 1B, a capacidade de extração de N-total pelos capins tifton 85 e elefante, em função das TCO aplicadas.

A concentração média de $\mathrm{N}$-total foi de $3,46 \mathrm{dag} \mathrm{kg}^{-1}$, no capim tifton 85 e de 2,54 a 2,81 dag kg ${ }^{-1}$, no capim elefante. De acordo com os dados apresentados na Figura 1B e, em virtude do aumento proporcionado na produtividade, houve tendência de aumento na extração de $\mathrm{N}$-total pelo capim tifton, tendo-se obtido valor máximo estimado de $356 \mathrm{~kg} \mathrm{ha}^{-1}$, no SAC submetido à TCO de $570 \mathrm{~kg} \mathrm{ha}^{-1} \mathrm{~d}^{-1} \mathrm{de}$ DBO. Esta capacidade extratora foi inferior à obtida por Matos et al. (2009), de $802 \mathrm{~kg} \mathrm{ha}^{-1} \mathrm{de} \mathrm{N}$ total, em SAC utilizado no tratamento de águas residuárias de suinocultura (aplicação de $155 \mathrm{~kg} \mathrm{ha}^{-1} \mathrm{~d}^{-1}$ de DBO), cultivados pelo tempo de 3 meses, e por Queiroz et al. (2004) que obtiveram extração de $552 \mathrm{~kg} \mathrm{ha}^{-1}$ de N-total quando o mesmo capim foi cultivado sob carga de $175 \mathrm{~kg} \mathrm{ha}^{-1} \mathrm{~d}^{-1}$ de N-total, em 4 meses de aplicação contínua da mesma água residuária.

Considerando-se mantidas a concentração na parte aérea e as produtividades do capim tifton 85 e elefante ao longo do ano, o que pode ser considerado conservativo, tendo em vista que o cultivo ocorreu no período de inverno-primavera, sabidamente de menor crescimento das plantas, as estimativas de absorção de nitrogênio ficariam na faixa de 66 a 144 e média de $123 \mathrm{~g} \mathrm{~m}^{-2}$ ano ${ }^{-1}$, respectivamente, superiores às reportadas por Reddy \& DeBusk (1985), que obtiveram 12 a $120 \mathrm{~g} \mathrm{~m}^{-2}$ ano $^{-1}$ no cultivo de macrófitas emergentes em SAC.

A concentração de P-total na parte aérea do capim elefante ficou em média $0,39 \mathrm{dag} \mathrm{kg}^{-1}$ e no capim tifton 85 ficou em média de $0,36 \mathrm{dag} \mathrm{kg}^{-1}$ (Figura 1C). A estimativa de extração pelo capim tifton 85 ficou na faixa de 15,7 a $37,8 \mathrm{~kg} \mathrm{ha}^{-1}$, aumentando com o aumento nas TCO aplicadas (Figura 1D).
Queiroz et al. (2004), trabalhando com o capim tifton 85 submetido à aplicação de água residuária da suinocultura em sistema de tratamento por escoamento superficial, obtiveram valor médio de $0,37 \mathrm{dag} \mathrm{kg}^{-1}$ de concentração de P-total nas folhas e remoção de $61 \mathrm{~kg} \mathrm{ha}^{-1}$ de fósforo, no tempo de 4 meses de cultivo; Matos et al. (2009) obtiveram resultados superiores
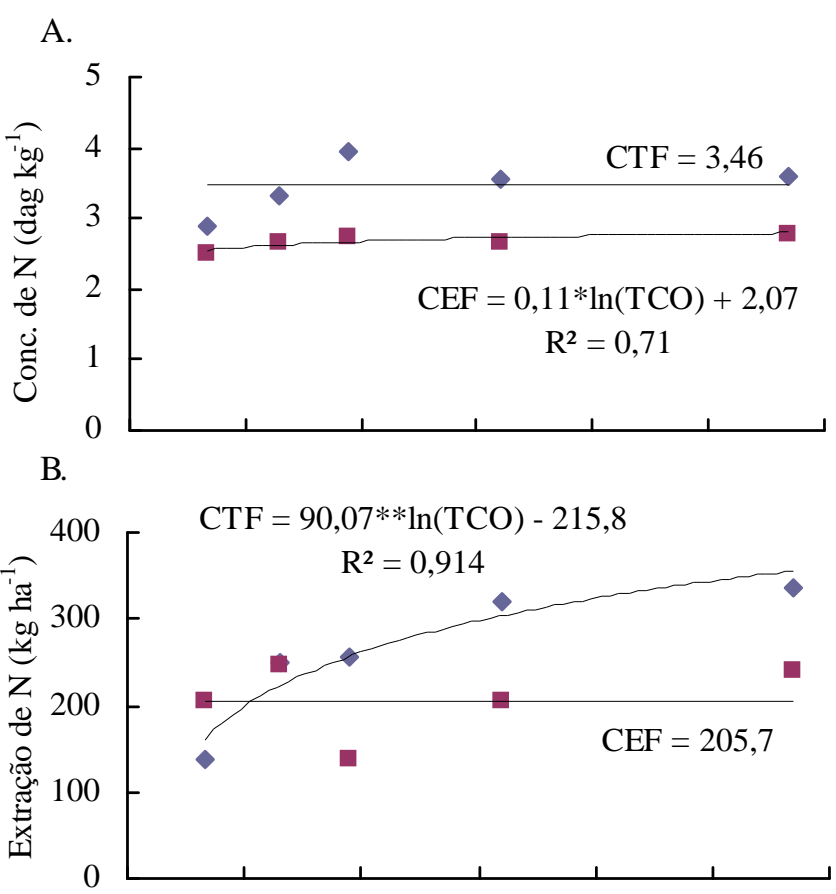

$$
\text { C. }
$$

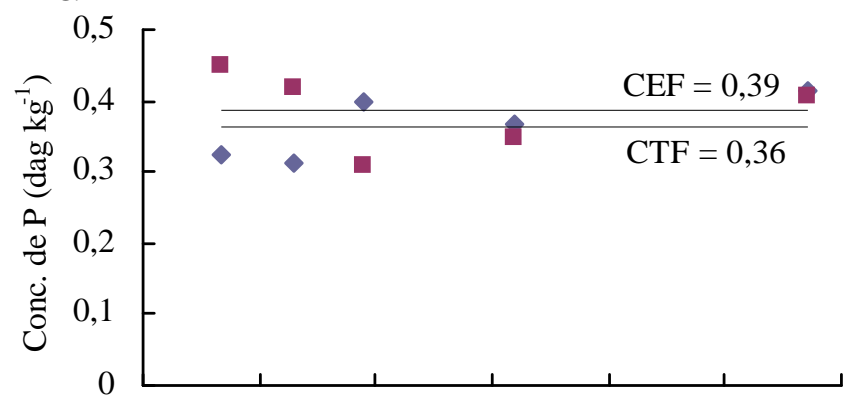

D.

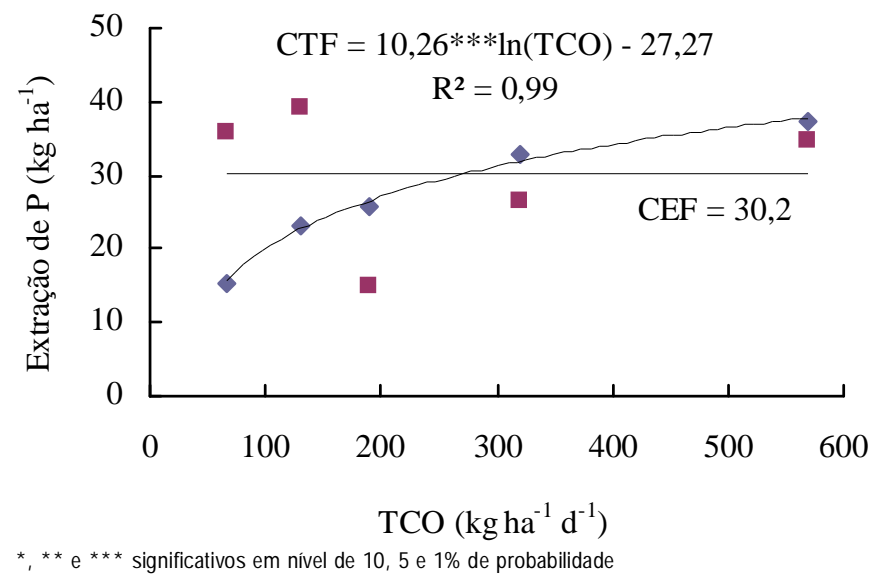

Figura 1. Concentração e extração de N-total e P-total pelos capins tifton 85 (CTF) e elefante (CEF) em função das taxas de carregamento orgânico superficial (TCO) aplicadas 
aos obtidos (extração de $120 \mathrm{~kg} \mathrm{ha}^{-1}$ ) quando cultivou o mesmo capim em SAC no tratamento de águas residuárias de suinocultura, no período de 3 meses de cultivo. Quanto ao capim elefante, verifica-se que os menores valores médios de concentração e de extração de P-total foram, respectivamente, de 0,39 dag kg $^{-1}$ e $30,17 \mathrm{~kg} \mathrm{ha}^{-1}$. Brasil et al. (2007) obtiveram remoção de $302 \mathrm{~kg} \mathrm{ha}^{-1} \mathrm{ano}^{-1}$ de fósforo em SAC, em escala reduzida, cultivado com capim elefante, durante 3 meses, no tratamento de águas residuárias da suinocultura.

Tal como já discutido em relação ao N-total, os resultados obtidos neste trabalho de extração de P-total pelas plantas são majorados, caso se considere período de cultivo de um ano. Mantidas a concentração e a produtividade durante todo o ano, estimaram-se extrações de P-total na faixa de 6 a $15 \mathrm{~g} \mathrm{~m}^{-2}$ ano $^{-1}$, com o capim tifton 85 , e média de $18 \mathrm{~g} \mathrm{~m}^{-2}$ ano $^{-1}$, com o capim elefante, taxas de remoção semelhantes às que foram obtidas por Reddy \& DeBusk (1985), de 1,8 a $18 \mathrm{~g} \mathrm{~m}^{-2}$ ano $^{-1}$, em macrófitas emergentes, e um pouco superiores às obtidas por Vymazal (2004), que foram de 0,4 a $10,5 \mathrm{~g} \mathrm{~m}^{-2} \mathrm{ano}^{-1} \mathrm{em}$ Phalaris arundinacea; de 0,6 a 9,8 $\mathrm{g} \mathrm{m}^{-2}$ ano $^{-1} \mathrm{em}^{\text {Phragmites australis }}$ e de 0,2 a $6,5 \mathrm{~g} \mathrm{~m}^{-2}$ ano $^{-1}$ em Typha spp.

Com o intuito de se avaliar o valor nutricional dos capins cultivados, fez-se uma comparação da sua qualidade com padrões estabelecidos pela NRC $(1984$; 1988) para alimentação de bovinos. Os valores médios de concentração de fósforo obtidos em ambas as espécies (Figura 1C) demonstraram que essas forrageiras atenderiam às exigências nutricionais para alimentação de bovinos de corte (considerando-se uma massa viva de $454 \mathrm{~kg}$ ), ao se consumir cerca de $2,2 \%$ do valor dessa massa, em termos de matéria seca (neste caso, a concentração de $\mathrm{P}$ na forrageira teria de ser maior que $0,19 \mathrm{dag} \mathrm{kg}^{-1}$ ) e também para vacas em lactação, considerando-se $590 \mathrm{~kg}$ massa viva produzindo, em média, $20 \mathrm{~kg} \mathrm{~d}^{-1}$ de leite e consumindo, em média, 3,0\% do valor dessa massa viva, em termos de matéria seca (neste caso, a concentração de P na forrageira teria de ser maior que $0,34{\mathrm{dag} \mathrm{kg}^{-1}}^{-}$).

Nos SAC cultivados com capim elefante a concentração média de potássio foi de $1,92 \mathrm{dag} \mathrm{kg}^{-1}$ e nos $\mathrm{SAC}$ cultivados com capim tifton 85 o valor médio foi de $1,41 \mathrm{dag} \mathrm{kg}^{-1}$ (Figura 2A). No que se refere à extração de potássio, observou-se um valor médio de $150,1 \mathrm{~kg} \mathrm{ha}^{-1}$ de extração de $\mathrm{K}$ pelo capim elefante enquanto nos SAC cultivados com o capim tifton 85 foi estimada na faixa de 75,9 a 129,2 $\mathrm{kg} \mathrm{ha}^{-1}$, crescente com o aumento na TCO aplicada (Figura 2B). Queiroz et al. (2004), ao cultivarem capim tifton 85 submetido à aplicação contínua de $91 \mathrm{~kg} \mathrm{ha}^{-1} \mathrm{dia}^{-1}$ de $\mathrm{K}$ contido em água residuária da suinocultura, durante 4 meses, em sistema de tratamento por escoamento superficial, obtiveram um valor médio de $591 \mathrm{~kg} \mathrm{ha}^{-1}$ de extração de potássio. Resultados superiores $\left(642 \mathrm{~kg} \mathrm{ha}^{-1}\right)$ foram obtidos por Matos et al. (2009) com o mesmo capim, cultivado por 3 meses em SAC utilizado no tratamento de águas residuárias de suinocultura. Da mesma forma como já dito em relação ao $\mathrm{Ne} \mathrm{P}$, os valores de extração obtidos neste trabalho passam a ser maiores quando são considerados iguais períodos de cultivo. A taxa de extração média estimada com o cultivo em um ano, do capim elefante, foi de $899 \mathrm{~g} \mathrm{~m}^{-2} \mathrm{~d}^{-1}$ e do capim tifton 85 , na faixa de 308 a $524 \mathrm{~kg} \mathrm{ha}^{-1} \mathrm{~d}^{-1}$.
Gomide \& Queiroz (1994) consideraram a concentração na faixa de 1,5 a 2,0 dag $\mathrm{kg}^{-1}$ normal para forrageiras com bom suprimento de potássio e que valores mais elevados indicam "absorção de luxo" (acima das necessidades nutricionais da planta) deste elemento, pelas diferentes espécies forrageiras. Com base nisto, pode-se afirmar que o capim elefante tendeu a apresentar índices normais de concentração de potássio, independente da TCO aplicada e que o capim tifton 85 tendeu

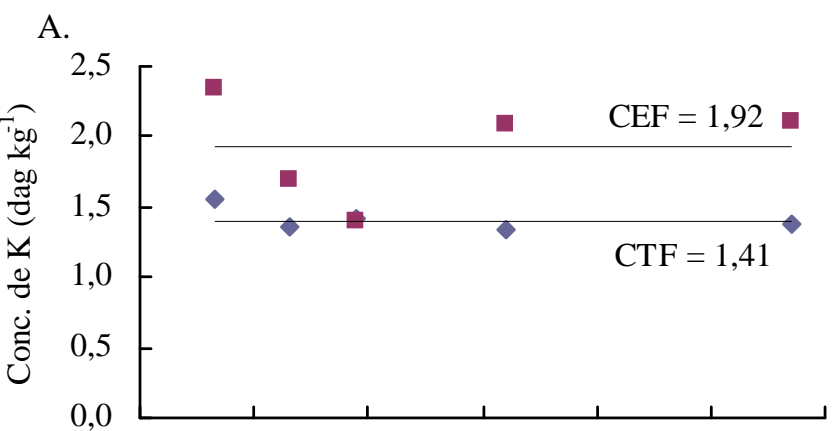

B.

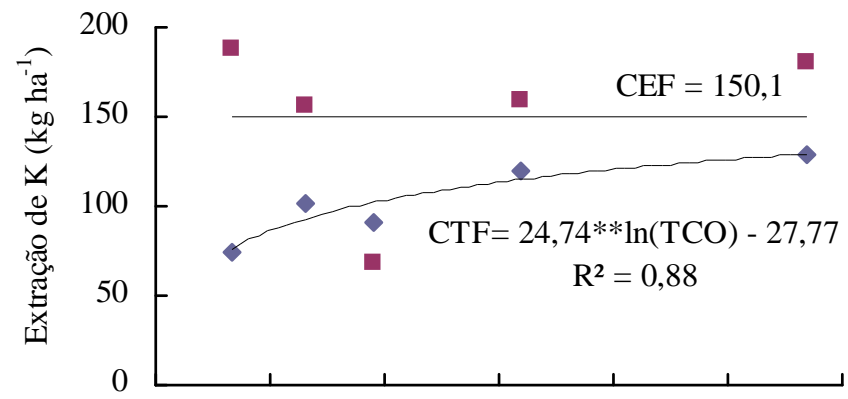

C.

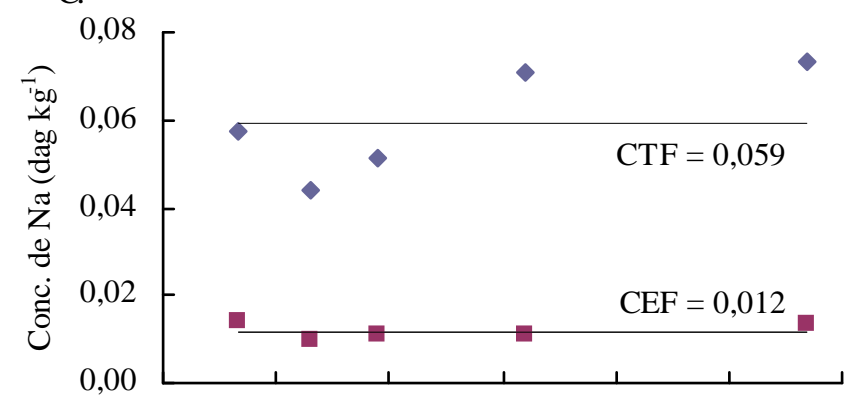

D.

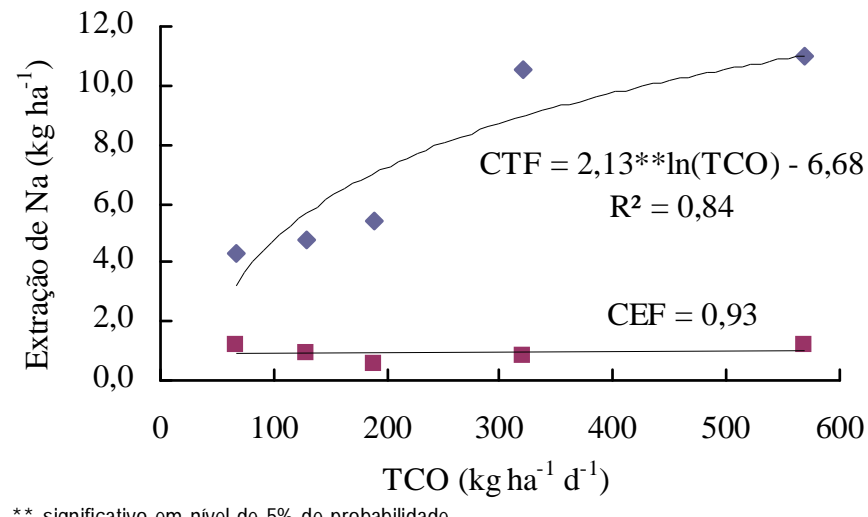

Figura 2. Concentração e extração de potássio e sódio pelos capins tifton 85 (CTF) e elefante (CEF) em função das taxas de carregamento orgânico superficial (TCO) aplicadas 
a apresentar índices abaixo do normal. Ainda assim, as concentrações de potássio nas forrageiras atenderiam às exigências para alimentação de vacas em lactação, que são de 0,90 dag $\mathrm{kg}^{-1}$ de $\mathrm{K}$ (NRC, 1988), e também às requeridas para bovinos de corte, que são de $0,65 \mathrm{dag} \mathrm{kg}^{-1} \mathrm{de} \mathrm{K}$, nas condições anteriormente citadas (NRC, 1984).

Na Figura 2C apresentam-se os valores de concentração e na Figura 2D, os valores de extração de sódio pelos capins tifton 85 e elefante, em função das TCO aplicadas.

Verificou-se que, em todos os tratamentos, o desempenho do capim tifton 85 foi superior ao do capim elefante, tanto em relação à capacidade de concentrar sódio na planta quanto à capacidade de extrair sódio da ARL. A concentração média de Na no capim tifton 85 foi de $0,059 \mathrm{dag} \mathrm{kg}^{-1}$ e no capim elefante foi de $0,012 \mathrm{dag} \mathrm{kg}^{-1}$. Maior diferença ocorreu nos tratamentos em que se utilizaram TCO de $320 \mathrm{~kg} \mathrm{ha}^{-1} \mathrm{~d}^{-1}$ de DBO, nos quais a concentração de sódio foi cerca de 6,5 vezes maior e a extração foi 7,4 vezes maior no capim tifton 85 do que no capim elefante, embora se obtenha, com base nos modelos ajustados, uma estimativa de ser 7,2 vezes na maior TCO (570 $\mathrm{kg} \mathrm{ha}^{-1} \mathrm{~d}^{-1} \mathrm{de}$ DBO).

A maior capacidade de extração de sódio pelo capim tifton 85 pode ser considerada grande virtude do capim quando se refere ao cultivo em SAC, já que este elemento químico é de difícil remoção em sistemas de tratamento de águas residuárias (Abou-Elela et al., 2010; Lo Monaco et al., 2004; 2009). Matos et al. (2009), ao aplicarem uma taxa de $154,8 \mathrm{~kg} \mathrm{ha}^{-1} \mathrm{~d}^{-1} \mathrm{de} \mathrm{DBO}$, por 3 meses, em SAC utilizado no tratamento de águas residuárias de suinocultura, obtiveram remoção de $10 \mathrm{~kg} \mathrm{ha}^{-1}$ pelo capim tifton 85, enquanto Queiroz et al. (2004), quando aplicaram continuamente, durante 4 meses, no mesmo capim, água residuária da suinocultura numa carga de $15 \mathrm{~kg} \mathrm{ha}^{-1} \mathrm{dia}^{-1}$ de $\mathrm{Na}$, obtiveram remoção de $6,6 \mathrm{~kg} \mathrm{ha}^{-1}$. Os resultados obtidos por esses autores foram semelhantes aos obtidos quando foram aplicados os maiores valores de TCO, embora possam ser considerados baixos quando comparados com os obtidos neste trabalho, caso sejam estimadas as quantidades que poderiam ser removidas caso o período de cultivo das plantas fosse o mesmo.

Como para atendimento do requerimento de bovinos de corte por sódio, segundo o NRC (1984), nas condições anteriormente especificadas, a concentração recomendável deste elemento químico deve ser superior a $0,10 \mathrm{dag}_{\mathrm{kg}}^{-1}$, e nenhuma das espécies estudadas neste trabalho atenderia às recomendações.

\section{CONCLUSÕES}

1. O capim tifton 85 foi capaz de absorver e extrair maior quantidade de $\mathrm{N}$ da água residuária de laticínios, quando cultivado em SAC, nas condições climáticas de Viçosa, MG, no período inverno-primavera de 2005.

2. A concentração de fósforo na parte aérea e a capacidade extratora foram semelhantes nos dois capins; entretanto, existem evidências de aumento na capacidade de extração deste nutriente pelo capim tifton 85 com o aumento da TCO aplicada noSAC.
3. Ao se comparar os valores de concentração e extração de $\mathrm{K}$ e Na pelas plantas, verifica-se que o capim elefante apresentou maior capacidade de extração de $\mathrm{K}$ enquanto o tifton 85 foi superior no que se refere ao $\mathrm{Na}$.

4. Considerando que o capim tifton 85 foi capaz de, em igual período de cultivo, extrair maior quantidade de N, Na e igual de $\mathrm{P}$, deve ser preferido em relação ao capim elefante, para cultivo em SAC utilizado no tratamento de águas residuárias de laticínios.

\section{LITERATURA CITADA}

Abou-Elela, S.I.; Kamel, M.M.; Fawzy, M.E. Biological treatment of saline wastewater using a salt-tolerant microorganism. Desalination, v.250, n.1, p.1-5, 2010.

APHA - American Public Health Association. Standard methods for the examination of water and wastewater. 21.ed. Washington: APHA, 2005. 1600p.

Brasil, M. S.; Matos, A. T. Avaliação de aspectos hidráulicos e hidrológicos de sistemas alagados construídos de fluxo subsuperficial. Engenharia Sanitária e Ambiental, v.13, n.3, p.323-328, 2008.

Brasil, M. S.; Matos, A. T.; Fia, R.; Silva, N. C. L. Desempenho agronômico de vegetais cultivados em sistemas alagados utilizados no tratamento de águas residuárias da suinocultura. Engenharia na Agricultura, v.15, n.3, p.307315, 2007.

Brasil, M. S.; Matos, A. T.; Soares, A. A.; Ferreira, P. A. Qualidade do efluente de sistemas alagados construídos, utilizados no tratamento de esgoto doméstico. Revista Brasileira de Engenharia Agrícola e Ambiental, v.9, p.133137, 2005.

Drumond, L. C. D.; Zanini, J. R.; Aguiar, A. P. A.; Rodrigues, G. P.; Fernandes, A. L. T. Produção de matéria seca em pastagem de Tifton 85 irrigada, com diferentes doses de dejeto líquido de suíno. Engenharia Agrícola, v.26, n.2, p.426433, 2006.

Fia, R.; Matos, A.T .; Ferreira, P. A.; Teodoro, P. E. P.; Schuery, F.C.; Luiz, F. A. R. Desempenho agronômico da Thypha sp. e alternanthera philoxeroides mart utilizadas no tratamento de águas residuárias da lavagem e descascamento/despolpa dos frutos do cafeeiro em sistema alagado construído. Engenharia na Agricultura, v.16, n.04, p.436-448, 2008.

Fia, R.; Matos, A. T.; Fia, F. R. L., Matos, M. P.; Lambert, T. F.; Nascimento F. S. Desempenho de forrageiras em sistemas alagados de tratamento de águas residuárias do processamento do café. Revista Brasileira de Engenharia Agrícola e Ambiental, v.14, n.8, p.842-847, 2010.

Gomide, J. A., Queiroz, D. S. Valor alimentício das Brachiarias. In: Simpósio Sobre Manejo da Pastagem, 11, 1994, Piracicaba. Anais... Piracicaba: FEALQ, 1994. p.223-248.

Kiehl, E. L. Fertilizantes orgânicos. Piracicaba: Agronômica Ceres, 1985. 492p.

Konnerup, D.; Koottatep, T.; Brix, H. Treatment of domestic wastewater in tropical, subsurface ûow constructed wetlands planted with Canna and Heliconia. Ecological Engineering, v.35, p.248-257, 2009. 
Lautenschlager, S. R. Modelagem do desempenho de Wetlands construídas. São Paulo: USP, 2001. 90p. Dissertação Mestrado

Lo Monaco, P. A. V.; Matos, A. T.; Jordão, C. P.; Cecon, P. R.; Martinez, M. A. Influência da granulometria da serragem de madeira como material filtrante no tratamento de águas residuárias da suinocultura. Revista Brasileira de Engenharia Agrícola e Ambiental, v.8, n.1, p.116-119, 2004.

Lo Monaco, P. A. V.; Matos, A. T.; Sarmento, A. P.; Lopes Júnior, A. V.; Lima, J. T. Desempenho de filtros constituídos por fibras de coco no tratamento de águas residuárias da suinocultura. Engenharia na Agricultura, v.17, n.6, p.473480, 2009.

Matos, A. T.; Abrahão, S. S.; Pereira, O. G. Desempenho agronômico de capim tifton 85 (Cynodon spp) cultivado em sistemas alagados construídos utilizados no tratamento de água residuária de laticínios. Ambi-Água, v.3, n.1, p.43-53, 2008.

Matos, A. T.; Freitas, W. S.; Lo Monaco, P. A. V. Eficiência de sistemas alagados construídos na remoção de poluentes de águas residuárias da suinocultura. Ambi-Água, v.4, n.2, p.31-45, 2009.

Matos, A. T.; Freitas, W. S.; Lo Monaco, P. A. V. Capacidade extratora de diferentes espécies vegetais cultivadas em sistemas alagados utilizados no tratamento de águas residuárias da suinocultura. Ambi-Água, v.5, n.2, p.119-132, 2010a.
Matos, A. T.; Freitas, W. S.; Martinez, M. A.; Tótola, M. R.; Azevedo, A. A. Tifton grass yield on constructed wetland used for swine wastewater treatment. Revista Brasileira de Engenharia Agrícola e Ambiental, v. 14, n.5, p.510-516, 2010 b.

Matos, A. T.; Lemos, A. F.; Barros, F. M. Mobilidade de nitrato em solos de rampas de tratamento de águas residuárias por escoamento superficial. Engenharia na Agricultura, v.12, n.1, p.57-65, 2004.

NRC - National Research Council. Nutrients requeriments of beef cattle. 6.ed. Washington: National Academy of Science, 1984.90p.

NRC - National Research Council. Nutrients requeriments of dairy cattle. 6.ed. Washington: National Academy of Science, 1988. 157p.

Queiroz, F. M.; Matos, A. T.; Pereira, O. G.; Oliveira, R. A.; Lemos, A. L. Características químicas do solo e absorção de nutrientes por gramíneas em rampas de tratamento de águas residuárias da suinocultura. Engenharia na Agricultura, v.12, n.2,p.77-90, 2004.

Reedy, K. R.; DeBusk, W. F. Nutrient removal potential of selected aquatic macrophytes. Journal of Environmental Quality, v.14, n.4, p.459-462, 1985.

Vymazal, J. Removal of phosphorus via harvesting of emergent vegetation in constructed wetlands for wastewater treatment. In: International Conference on Waste Stabilisation Ponds, 6, and International Conference on Wetland Systems for Water Pollution Control, 9, 2004. Proceedings... Avignon: IWA/ASTEE, 2004. CD-Rom. 